\title{
Electrical treeing and partial discharge characteristics of silicone rubber filled with nitride and oxide based nanofillers
}

\author{
A. H. M. Nasib ${ }^{1}$, M. H. Ahmad ${ }^{2}$, Z. Nawawi ${ }^{3}$, M. A. B. Sidik ${ }^{4}$, M. I. Jambak ${ }^{5}$ \\ ${ }^{1.2}$ Institute of High Voltage and High Current, School of Electrical Engineering, Faculty of Engineering, \\ Universiti Teknologi Malaysia, 81310 Skudai Johor, Malaysia \\ ${ }^{3,4,5}$ Department of Electrical Engineering, Faculty of Engineering, Universitas Sriwijaya, Palembang, \\ West Sumatera, Indonesia
}

\begin{tabular}{l} 
Article Info \\
\hline Article history: \\
Received Aug 6, 2018 \\
Revised Jun 23, 2019 \\
Accepted Oct 31, 2019 \\
\hline
\end{tabular}

\section{Keywords:}

Electrical treeing

Partial discharge

Silicon dioxide

Silicon nitride

Silicone rubber

\begin{abstract}
This article presents a study on electrical treeing performances with its associated partial discharge (PD) and the influence of filler concentration in silicone rubber $(\mathrm{SiR})$ samples which are filled with silicon dioxide $(\mathrm{SiO} 2)$ and silicon nitride (Si3N4) as nanofillers for electrical tree growth suppression. There are many researches on electrical treeing in SiR with $\mathrm{SiO} 2$ nanofillers but none of the publication have reported on Si3N4 nanofillers for suppression of the electrical tree growth. In this study, the treeing experiments were conducted by applying a fixed AC voltage of $10 \mathrm{kV}$ and $12 \mathrm{kV}$ at power frequency of $50 \mathrm{~Hz}$ on unfilled $\mathrm{SiR}, \mathrm{SiR} / \mathrm{SiO} 2$, and SiR/Si3N4 nanocomposites with different filler concentrations by 1, 3, and 5 weight percentage $(\mathrm{wt} \%)$ and the treeing parameters were observed with its correlated PD patterns. The outcome from this study found that the SiR/Si3N4 nanocomposites were able to withstand the electrical treeing better than the pure $\mathrm{SiR}$ or $\mathrm{SiR} / \mathrm{SiO} 2$ nanocomposites. Furthermore, the increase in filler concentration improved the electrical tree performances of the nanocomposites. This finding suggests the Si3N4 can be used as filler in polymeric insulating materials for electrical tree inhibition. Meanwhile, the PD activity shows increment when the tree progresses thereby indicating correlation in both parameters which can be as key parameter for monitoring unseen treeing in non-transparent samples.
\end{abstract}

Copyright () 2020 Institute of Advanced Engineering and Science. All rights reserved.

\section{Corresponding Author:}

Z. Nawawi,

Departement of Electrical Engineering,

Universitas Sriwijaya,

Palembang, West Sumatera, Indonesia.

Email: nawawi_z@yahoo.com

\section{INTRODUCTION}

Electrical treeing is a pre-breakdown phenomenon caused by endless electrical stress in polymeric insulations. Triggered by partial discharge (PD), electrical treeing occurs under electrical stress through tree like paths. The growth of an electrical tree consequences in the formation of a conductive path between the high-voltage and grounded parts of the insulation, therefore causing breakdown [1, 2]. Electrical tree activities have also been described to take place within the areas of weak points such as cable accessories due to electric field localization which is accompanied by PD. In application, cable accessories such as joints, terminations, and stress cones are usually made by silicone rubber (SiR). SiR has characteristics of both inorganic and organic materials. It also offers a number of benefits that not found in other organic rubber such as hydrophobic property, high temperature resistance, electrical insulation, good chemical stability, and flame retardants but it has poor solvent resistance and mechanical properties [3, 4]. In order to enhance the electrical tree resistance in the high-voltage cable accessories, different methods have been used by 
manufactures of SiR, such as improving material treatment, adding treeing inhibitors or fillers, modifying the material, etc $[5,6]$. Adding nanoparticles has lately drawn great attention with the potential of improving the physical, chemical, mechanical and electrical properties. Polymers such as Polyamide (PA), polyethylene (PE) and epoxy resin, etc. combined with nanoparticles including $\mathrm{MgO}, \mathrm{TiO} 2$, and, $\mathrm{SiO} 2$, etc. have been extensively studied [7-14]. Jamil et al examined the electrical tree propagation of SiR filled with organomontmorillonite (OMMT) and found that the nanoparticles were able to slow down the progression of the electrical treeing [15].

Hosier et al studied on low-density polyethylene (LDPE) polymer which used silicon dioxide (SiO2) as its filler and compared it with silicon nitride (Si3N4) as the filler. It stated Si3N4 provided potential pluses over an oxide based system through a reduction of surface hydroxyl groups and leading potentially to a composite with dielectric properties that are considerably less influenced by absorbed water or environmental effect. They found that nitride composites shows improved breakdown strength over oxide composites in all conditions they tested which are dry, ambient and wet [16, 17]. In spite of that improvement shown by Si3N4 as a filler, there are no researches have been carried out on the electrical tree performances associated with PD in SiR added with Si3N4 nanoparticles. Therefore, this paper presents electrical treeing associated with PD studies in SiR added with Si3N4 to suppress the growth of electrical treeing. In addition, the propagation length of the electrical trees was studied in order to investigate the performance of the $\mathrm{SiR} / \mathrm{Si} 3 \mathrm{~N} 4$ nanocomposites as well as the structure and the growth speed of trees and the electrical tree characteristics collectively discussed.

\section{RESEARCH METHOD}

\subsection{Material used}

The host polymer material is Sylgard 184 Silicone Elastomer which low in viscosity with dielectric strength, tensile strength and tears strength being $24 \mathrm{kV} / \mathrm{mm}, 6.2 \mathrm{MPa}$ and $2.7 \mathrm{kN} / \mathrm{m}$ respectively. The silicon dioxide is supplied by Sigma Aldrich which is was fumed silicon dioxide with an average size of $12 \mathrm{~nm}$. Silicon nitride is supplied by NanoAmor with average size of 15-30 nm. Hardener used is dimethyl methylhydrogen siloxane (DMS) which mixed with polymer in the ratio of 10: 1 (silicone rubber: hardener) [18].

\subsection{Preparation of silicone rubber nanocomposites}

The silicone rubber ( $\mathrm{SiR})$ Sylgard 184 was used in form of leaf-like specimen. The needle-plane electrode geometry was engaged for initiation and propagation of electrical treeing. The gap distance between the needle tip and the plane electrode was adjusted to $1 \mathrm{~mm}$. Silicon dioxide (SiO2) and silicon nitride (Si3N4) nanoparticles were dried at $100{ }^{\circ} \mathrm{C}$ for 24 hours using conventional vacuum oven to remove moisture. After preconditioning of nanofillers, it was mixed with the SiR varies by 1,3 and 5 weight percentage (wt\%) using magnetic stirrer at room temperature for 30 minutes at $60 \mathrm{rpm}$. Then, the nanofillers were dispersed using an ultrasonicator to obtain a homogeneous dispersion for 1 hour [19]. After that, the $\mathrm{SiR}$ nanocomposite compound were mixed with its hardener (ratio 10:1) for 30 minutes at $125 \mathrm{rpm}$ using a magnetic stirrer at room temperature. The specimen was cured at $100{ }^{\circ} \mathrm{C}$ for 45 minutes. The specimen was prepared in form of leaf-like as shown in Figure 1.

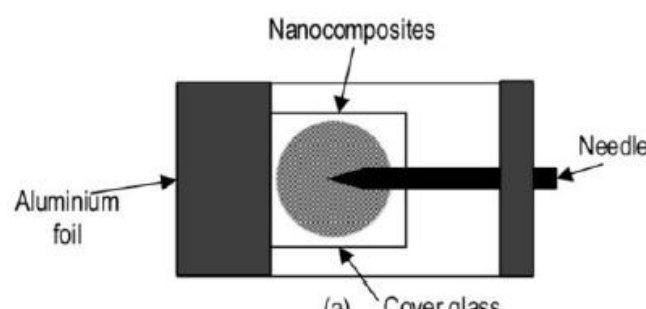

(a) Cover glass

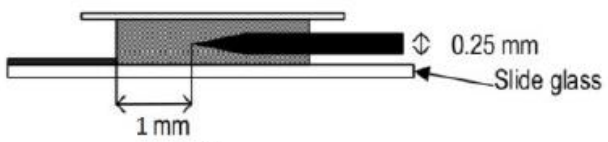

(b)

Figure 1. Configuration of leaf like specimen (a) top view (b) side view 


\subsection{Test sample preparation}

To study the electrical treeing and its partial discharge (PD), online monitoring system was developed in this work which consists of a stereomicroscope, an oscilloscope, a personal computer, and a charge-coupled device (CCD) camera as shown in Figure 2. The system consisted of an Olympus SZX16 Research stereo microscope that equipped with auxiliary DP 26 Olympus CCD camera with $115 \mathrm{x}$ magnification capability which sufficient to capture magnified images of electrical tree propagation. Measuring impedance was used to detect the PD pulses together with the Coupling-capacitor which is the voltage divider so the voltage does not rise on the impedance of the PD [20]. The purpose of this procedure was to observe electrical treeing growth optically and its associated PD at room temperature.

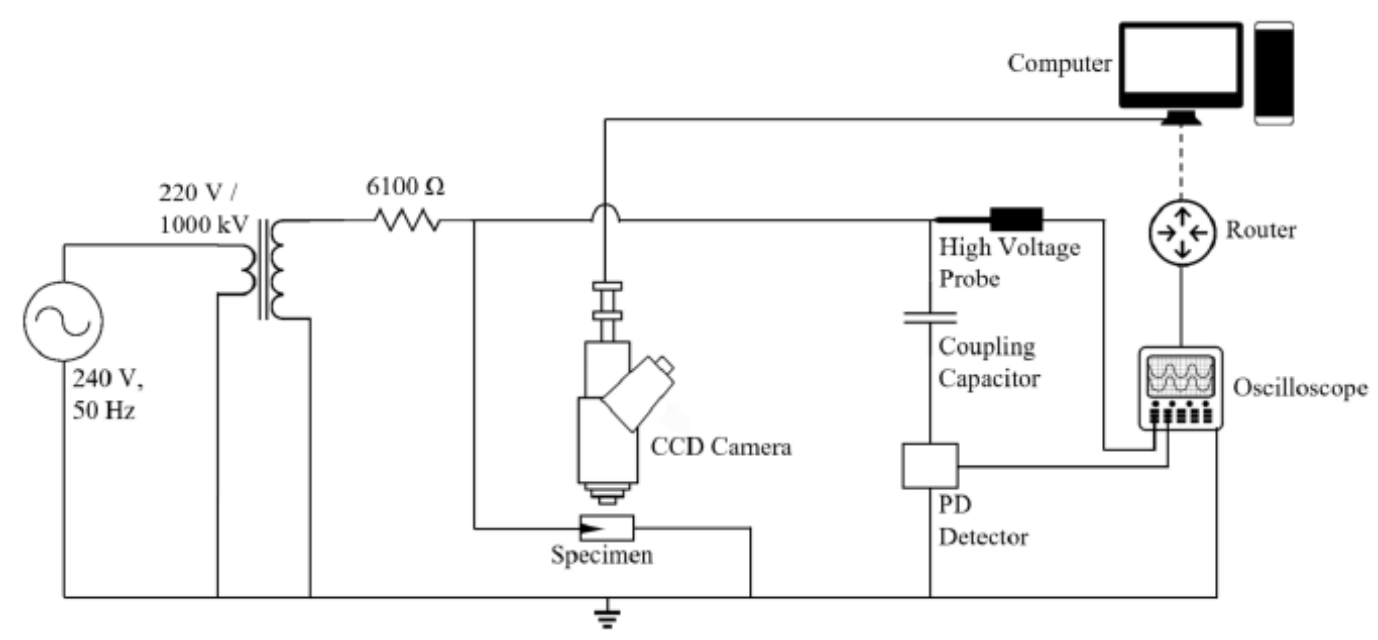

Figure 2. Schematic diagram of experimental setup for electrical treeing studies

The experiments were conducted to record the tree growth and PD by applying a constant AC voltage of $10 \mathrm{kV}$ and $12 \mathrm{kV}$ at $50 \mathrm{~Hz}$ which the voltage is monitored using oscilloscope. The samples were placed inside an acrylic cell containing silicone oil to avert surface flashover. Tree growth was constantly observed using the specially established method. The microscope and the CCD camera were interfaced through a computer. The images of electrical treeing at test voltage were captured and recorded. During electrical tree growth, the real time images of electrical tree were taken using CCD camera fixed at stereo microscope with the assist of CellSens digital imaging software. The PD reading was continually monitored by PD detector and oscilloscope which then recorded to the computer by LabVIEW programme.

\section{RESULTS AND ANALYSIS}

The tree initiation time, tree bridging time, tree propagation length and partial discharge (PD) of the investigated nanocomposite samples were analysed. Figure 3 shows the photograph of the electrical tree captured by the microscope at different stages.

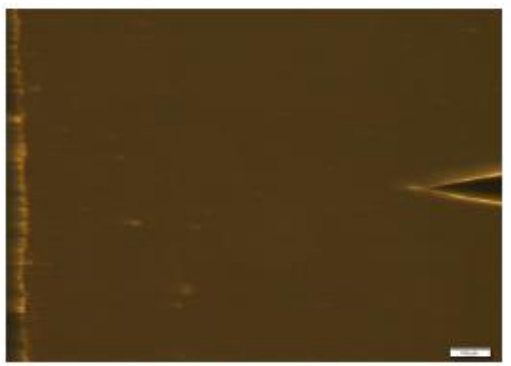

(a)

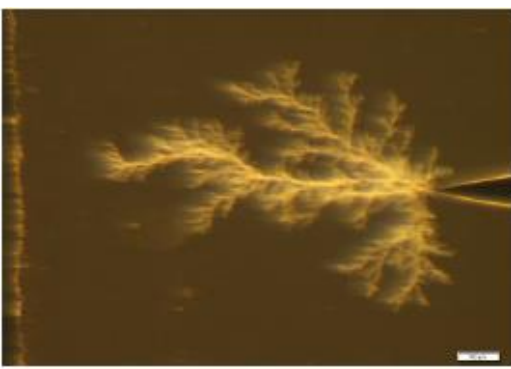

(b)

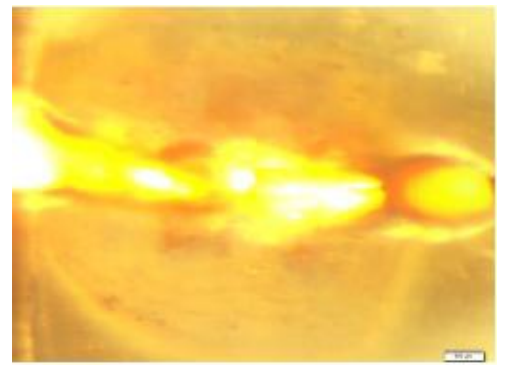

(c)

Figure 3. Electrical treeing (a) initiation stage (b) propagation stage and (c) bridging stage 


\subsection{Tree initiation time}

The tree initiation time ( $\mathrm{Ti}$ ) of an electrical tree is the time at which small, observable trees initiate at the needle tip. Figures 4(a) \& 4(b) show the Ti of the electrical trees of SiR, with nanofillers of $\mathrm{SiO} 2$ and Si3N4 that varies by $0,1,3$, and $5 \mathrm{wt} \%$. Under $10 \mathrm{kV}$ injection, the average Ti for unfilled $\mathrm{SiR}$ was $7.34 \mathrm{~s}$, while the average $\mathrm{Ti}$ for $\mathrm{SiR} / \mathrm{SiO} 2$ were $6.04 \mathrm{~s}, 5.68 \mathrm{~s}$, and $8.99 \mathrm{~s}$ for 1 , 3, and $5 \mathrm{wt} \%$, respectively; the SiR/Si3N4 showed a faster Ti of $5.28 \mathrm{~s}, 5.68 \mathrm{~s}$, and $7.57 \mathrm{~s}$. Meanwhile, with $12 \mathrm{kV}$ injection, the average Ti for pure SiR was $6.86 \mathrm{~s}$, while the average Ti for $\mathrm{SiR} / \mathrm{SiO} 2$ were $6.86 \mathrm{~s}, 6.75 \mathrm{~s}$, and $10.65 \mathrm{~s}$ for 1, 3, and 5 wt\%, respectively; the SiR/Si3N4 showed a faster Ti of 6.93 s, 6.04 s, and 7.10 s respectively. Results from this statistical analysis show that for the Ti, only a small difference exists between the pure and two different nanofiller types. Most of the initiation times are only between 5 to 12 seconds.

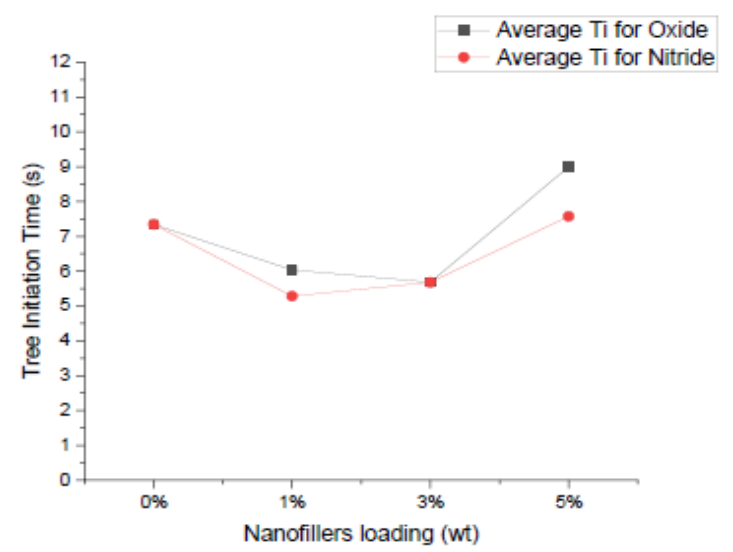

(a)

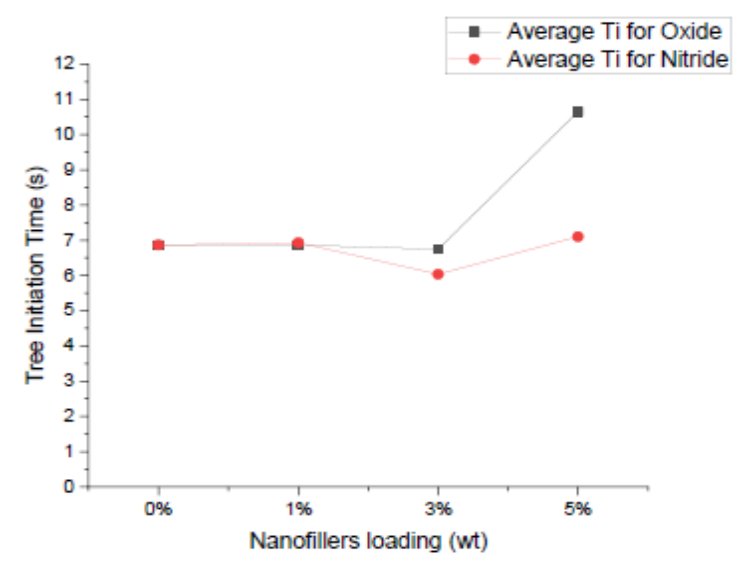

(b)

Figure 4. Tree initiation time for Pure, $\mathrm{SiR} / \mathrm{SiO} 2$, and $\mathrm{SiR} / \mathrm{Si} 3 \mathrm{~N} 4$ nanocomposites with varies loading levels at voltage of (a) $10 \mathrm{kV}$ and (b) $12 \mathrm{kV}$

The result shows that the tree initiation times of the nanocomposites varied based on the nanofillers type and filler loading used. There is an increment in the initiation time for the $5 \mathrm{wt} \%$ loading sample; however, the difference is too small. This result is different with the result from Jamil et al.'s work; which they showed that even small amounts of added nanofiller led to significant improvements in tree initiation times as the nanocomposites with nanofillers took a long time to initiate compared to unfilled SiR. This finding difference occur as the current study use a shorter distance of $1 \mathrm{~mm}$ between the high-voltage and ground compared to the previous study that use a longer distance which is $2 \mathrm{~mm}$. Generally, the nanocomposites played a role in prolonging tree initiation times compared to unfilled polymer, because the trapped charges needed higher energy to be extracted from the polymer; more time was thus required for the tree to initiate within the nanocomposites [21]. However, if the distance between the high-voltage and ground is too short, energy needed for the trapped charges to be extracted from the polymer is lower; thus the tree is easier to initiate within the nanocomposites.

\subsection{Tree propagation length}

Figure 5 shows the result of electrical tree performance for the SiR nanocomposites with different nanofillers at 1, 3, and $5 \mathrm{wt} \%$ filler loading. The unfilled SiR showed the fastest propagation rate, followed by $\mathrm{SiR} / \mathrm{SiO} 2$ nanocomposites. $\mathrm{SiR} / \mathrm{Si} 3 \mathrm{~N} 4$ exhibited the slowest propagation time. Similar results were observed for the rest of the samples. It can be seen from Figure 5 that the tree propagation increased with an increase in nanofillers loading. These results are in line with other studies that have been conducted in which higher filler concentrations led to densely packed structures for resisting electrical tree progression. The tree channels needed to propagate through the interfaces of the nanofiller in the packed structures of the polymer, which resulted in longer propagation times [11, 22-24]. From Figure 5, it is suggested that $\mathrm{Si}_{3} \mathrm{~N}_{4}$ nanofillers has a strong ability to slow down the electrical tree growth. This result agrees with Hosier et al.'s work, in which Polyethylene/nitride nanocomposites exhibited higher breakdown voltage, thus indicating that nitride nanocomposites has ability in resistance against electrical treeing [16]. 


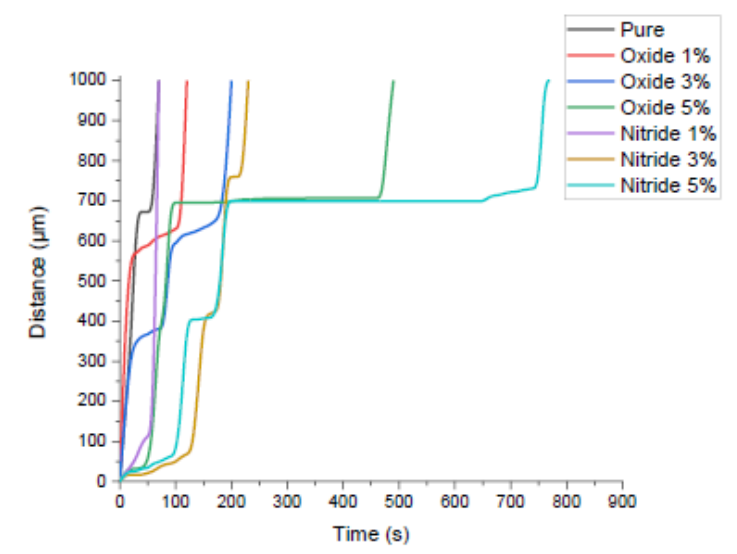

(a)

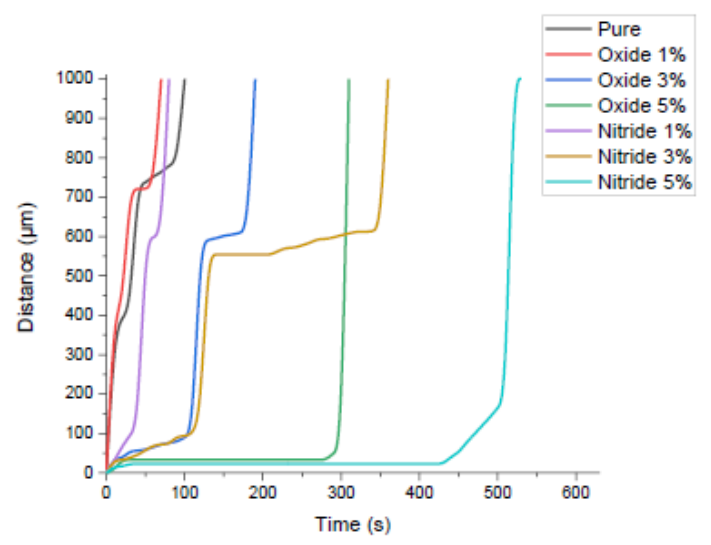

(b)

Figure 5. Tree propagation lengths across nanocomposites with varies loading levels at voltage of (a) $10 \mathrm{kV}$ and (b) $12 \mathrm{kV}$

\subsection{Tree bridging time}

Figure 6 shows the average tree bridging time $(\mathrm{Tb})$ for Pure, SiR/SiO2, and SiR/Si3N4 with different nanofiller loadings. $\mathrm{Tb}$ is the time taken for the tree to reach the ground electrode, which in our study was at $1000 \mu \mathrm{m}$ from the high-voltage electrode. It is confirmed that both $\mathrm{SiR} / \mathrm{SiO} 2$ and $\mathrm{SiR} / \mathrm{Si} 3 \mathrm{~N} 4$ nanocomposites improved the tree bridging time compared to unfilled SiR.

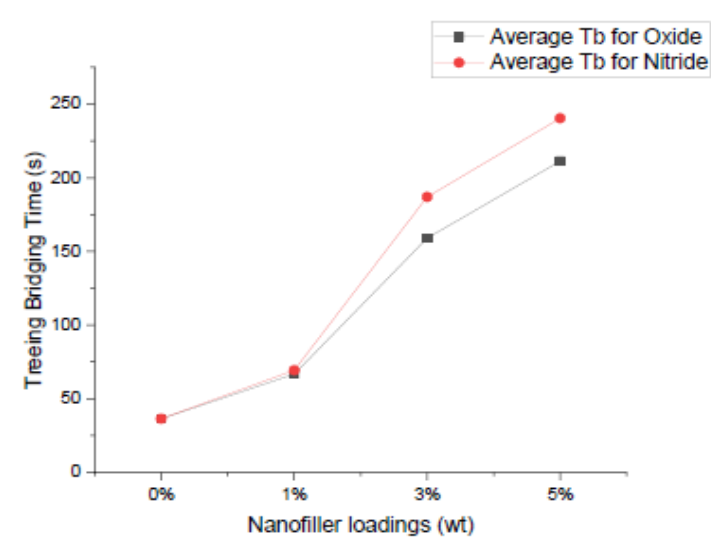

(a)

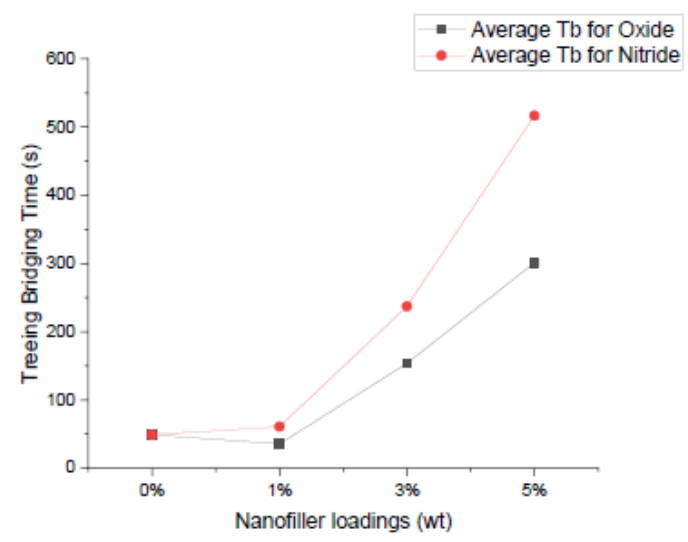

(b)

Figure 6. Tree bridging time for Pure, $\mathrm{SiR} / \mathrm{SiO} 2$, and $\mathrm{SiR} / \mathrm{Si} 3 \mathrm{~N} 4$ nanocomposites with varies loading levels at voltage of (a) $10 \mathrm{kV}$ and (b) $12 \mathrm{kV}$

From Figure 6 (a), the unfilled $\mathrm{SiR}$ recorded the shortest $\mathrm{Tb}$ result, followed by $\mathrm{SiR} / \mathrm{SiO} 2$ and $\mathrm{SiR} / \mathrm{Si} 3 \mathrm{~N} 4$ nanocomposites. The average $\mathrm{Tb}$ of the unfilled $\mathrm{SiR}$ was $36.45 \mathrm{~s}$, while the $\mathrm{Tb}$ for $\mathrm{SiR} / \mathrm{SiO} 2$ nanocomposite were $66.74 \mathrm{~s}, 159.04 \mathrm{~s}$, and $211.34 \mathrm{~s}$ for 1,3 , and $5 \mathrm{wt} \%$, respectively. SiR/Si3N4 nanocomposites showed the longest $\mathrm{Tb}$ of $69.30 \mathrm{~s}, 186.97 \mathrm{~s}$, and $240.45 \mathrm{~s}$ for the same three wt\%, respectively. From Figure 6 (b), the $12 \mathrm{kV}$ injection show a same pattern of $\mathrm{Tb}$ as the $10 \mathrm{kV}$ injection. The unfilled SiR recorded the shortest $\mathrm{Tb}$ result, followed by $\mathrm{SiR} / \mathrm{SiO} 2$ and $\mathrm{SiR} / \mathrm{Si} 3 \mathrm{~N} 4$ nanocomposites. The average $\mathrm{Tb}$ of the unfilled $\mathrm{SiR}$ was $48.57 \mathrm{~s}$, while the $\mathrm{Tb}$ for $\mathrm{SiR} / \mathrm{SiO} 2$ nanocomposite were $35.26 \mathrm{~s}$, $153.72 \mathrm{~s}$, and $301.04 \mathrm{~s}$ for 1,3 , and $5 \mathrm{wt} \%$, respectively. SiR/Si3N4 nanocomposites showed the longest $\mathrm{Tb}$ of $60.83 \mathrm{~s}, 237.14 \mathrm{~s}$, and $516.88 \mathrm{~s}$ for the same three wt\%, respectively.

From these results, it is clear that the $\mathrm{Tb}$ of electrical treeing increased with an increase in the nanofiller loading. SiR/Si3N4 nanocomposites showed the longest $\mathrm{Tb}$ when compared to pure SiR and $\mathrm{SiR} / \mathrm{SiO} 2$ nanocomposites. The result shows that the tree bridging time of the nanocomposites is also dependent on filler type and the nanofiller loading. Nanocomposites with nanofiller take a longer time to 
break down compared to unfilled $\mathrm{SiR}$. In addition, the $\mathrm{Tb}$ increased with an increase in nanofiller concentration. Overall, this result showed that $\mathrm{SiR} / \mathrm{Si} 3 \mathrm{~N} 4$ nanocomposites has a longer breakdown time than the other nanocomposites. This result agrees with $\mathrm{Xu}$ et al.'s work, in which Polypropylene/nitride nanocomposites exhibited higher breakdown voltage and longer endurance under constant electrical stress [25].

\subsection{Partial discharge patterns}

In this study, it is discovered that when the tree structure grows longer and more compound, the intensity and frequency of partial discharge (PD) events are greater. Table 1 and Table 2 show phase resolved partial discharge (PRPD) patterns recorded along the electrical treeing growth with each dots representing single PD event. The PD activities occur generally only in the 1 st quadrant (phases of $0^{\circ}$ to $90^{\circ}$ ) and 3 rd quadrant (phases of $180^{\circ}$ to $270^{\circ}$ ), where the $\mathrm{AC}$ voltage rises to the positive or negative value respectively [26].

Table 1. PRPD patterns on three following AC cycles after its first PD event for a tree grown at $10 \mathrm{kV}$ on the three type of samples

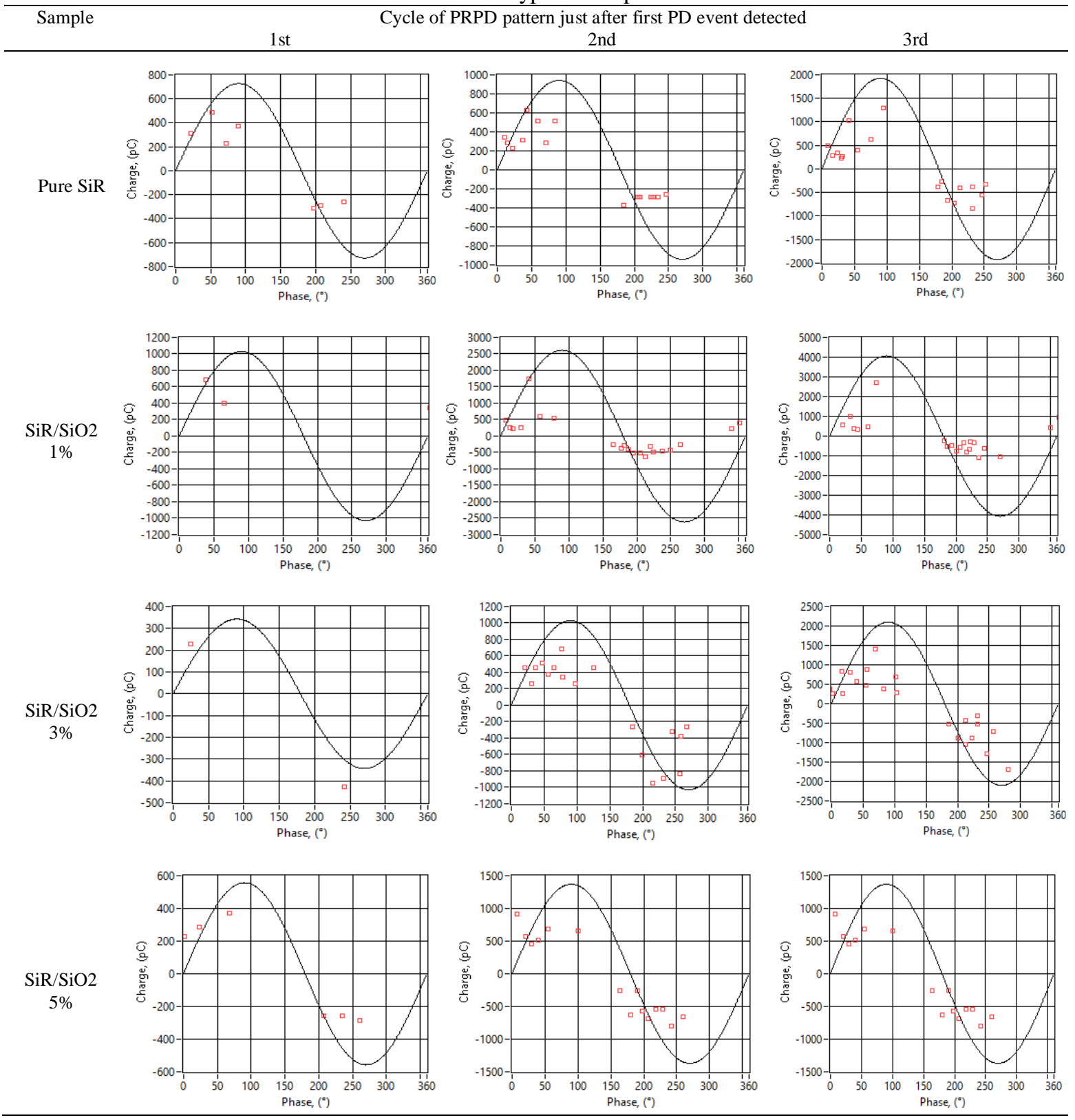


Table 1. PRPD patterns on three following AC cycles after its first PD event for a tree grown at $10 \mathrm{kV}$ on the three type of samples (continue)

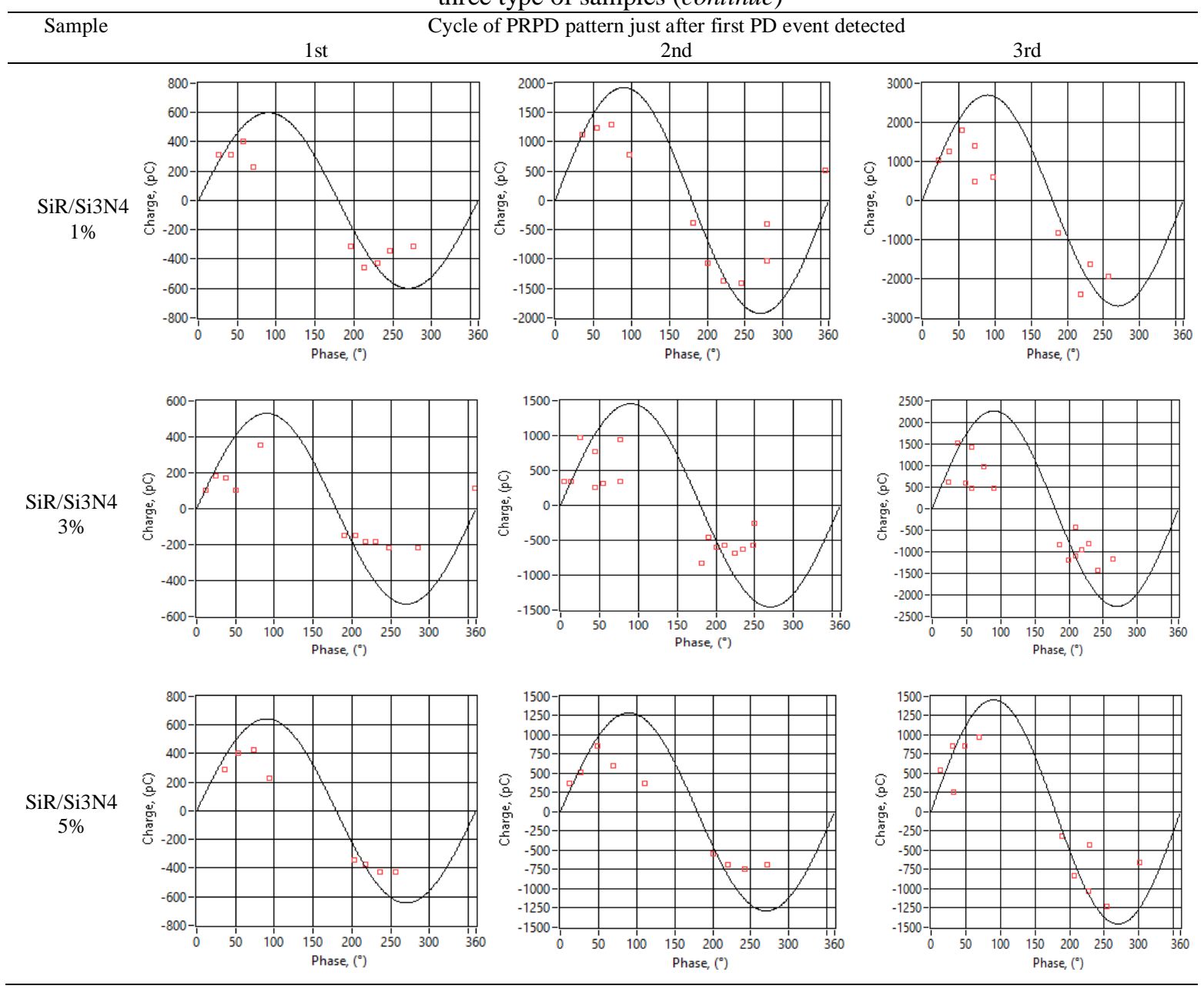

Table 2. PRPD patterns on three following AC cycles after its first PD event for a tree grown at $12 \mathrm{kV}$ on the three type of samples

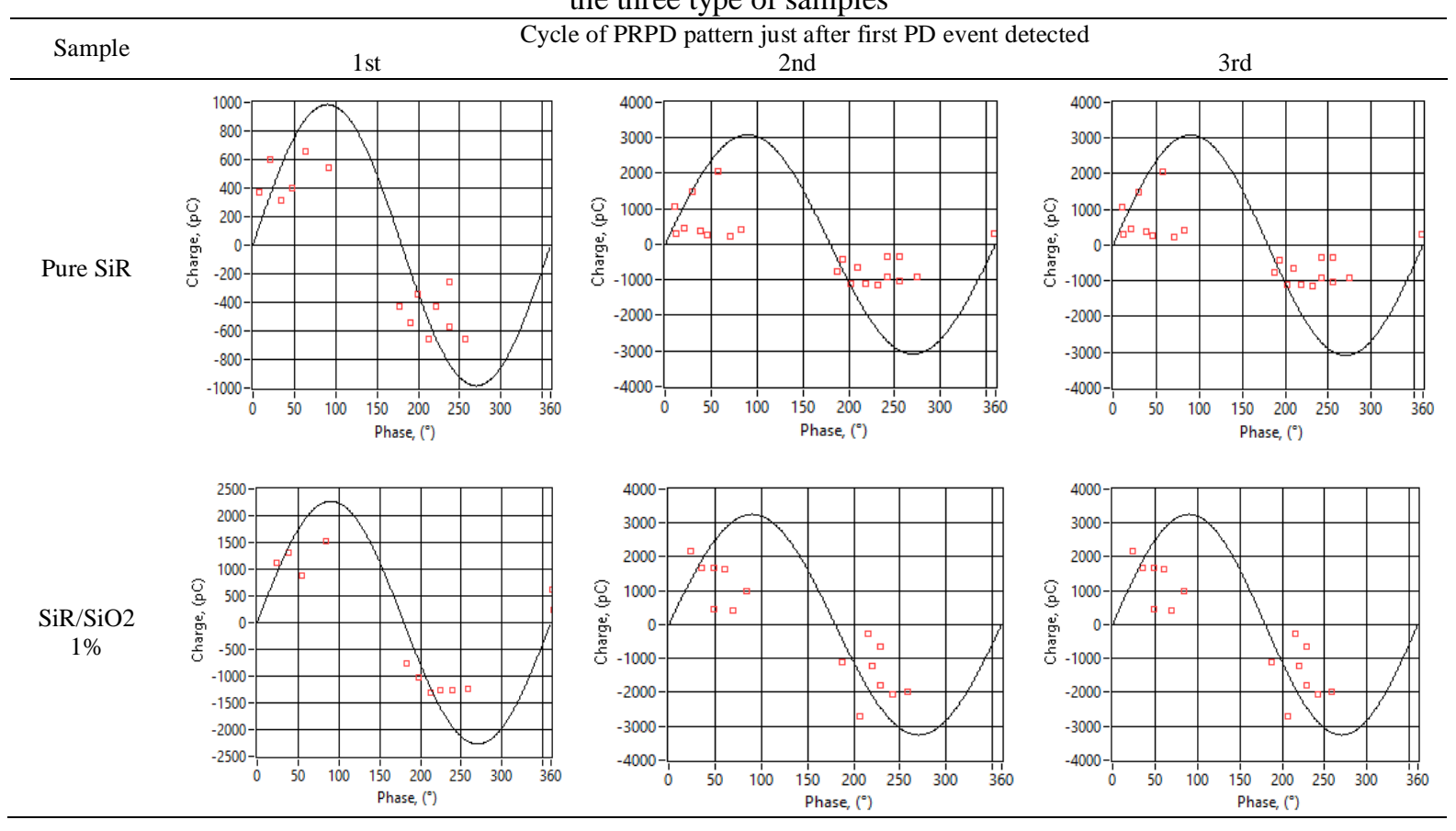

Int J Elec \& Comp Eng, Vol. 10, No. 2, April 2020 : 1682 - 1692 
Table 2. PRPD patterns on three following AC cycles after its first PD event for a tree grown at $12 \mathrm{kV}$ on the three type of samples (continue)

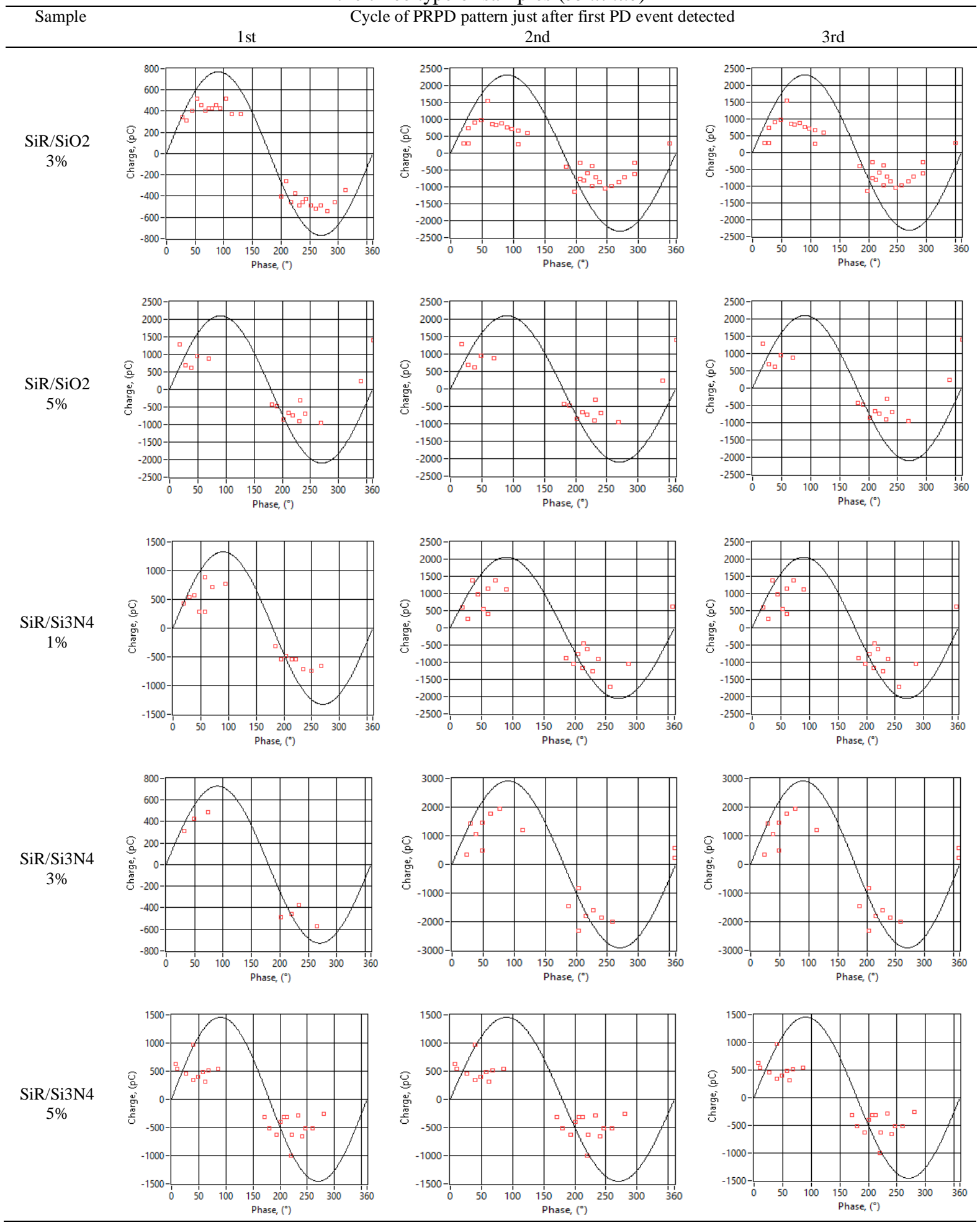

From the PRPD pattern in Table 1 and Table 2, it is noted that the intensity and frequency of PD events increased by cycle. For example, as shown in the Table 1 from the pure SiR sample, the 1st AC cycle shows only a few level discharge which is lower than $600 \mathrm{pC}$, then it builds up to greater than $600 \mathrm{pC}$ in the 2 nd AC cycle and finally up to more than $1000 \mathrm{pC}$ in the $3 \mathrm{rd}$ AC cycle as the tree approaches the ground. Similar behaviour can also be seen in other samples of $\mathrm{SiR}, \mathrm{SiR} / \mathrm{SiO} 2$ and SiR/Si3N4 nanocomposites as shown in Table 1 and Table 2. From these patterns, it is certain that PD activity are related to the extent of 
tree growth. Thus, the behaviour of tree growth in the later stage that can be shown by a high level of PD activity is potentially to be applied in plant use which is to identify the presence of damage of the insulation which is caused by the electrical treeing [26]. Moreover, the PD magnitude of $5 \mathrm{wt} \%$ of silicone rubber nanocomposite with $5 \mathrm{wt} \%$ showing similar pattern behaviours interestingly but the magnitude shows the lowest PD magnitude among other silicone rubber nanocomposites with $1 \mathrm{wt} \%$ and $3 \mathrm{wt} \%$. This PD behaviours are linked with the electrical tree suppression behaviours as the $\mathrm{Si}_{3} \mathrm{~N}_{4}$ with the appropriate amount of $5 \mathrm{wt} \%$ has contributed to the slowest propagation of treeing and the lowest PD magnitude. Therefore, this study has shown that the $\mathrm{Si}_{3} \mathrm{~N}_{4}$ nanofillers can be more effective that the $\mathrm{SiO}_{2}$ nanofillers in resisting the growth of electrical treeing in silicone rubber nanocomposites.

\section{CONCLUSION}

Electrical treeing and partial discharge (PD) studies on silicon nitride (Si3N4) and silicon dioxide ( $\mathrm{SiO} 2)$ nanofillers added to silicone rubber $(\mathrm{SiR})$ focusing on electrical treeing investigation has been presented in this paper. As a result, the following conclusions were obtained; the presence of $\mathrm{SiO} 2$ and $\mathrm{Si} 3 \mathrm{~N} 4$ nanofillers in SiR had slowed down the growth of electrical treeing thereby acting as electrical tree retardants. The increase in filler concentration has also resulted in better electrical treeing suppression performance. Furthermore, the improved performance of SiR/ $5 \mathrm{wt} \% \mathrm{Si} 3 \mathrm{~N} 4$ nanocomposite was observed in this study which that it has the best improvement on the electrical tree propagation time and tree growth rates compared to unfilled $\mathrm{SiR}$ and $\mathrm{SiR} / \mathrm{SiO} 2$ nanocomposite. In light of this, it can be concluded that Si3N4 nanofiller has a good potential to be used as an additive in polymeric insulating material to retard the electrical tree growth in insulation. Then, it is found that the associated PD activities intensify from the treeing initiation until the bridging. The relationship between PD activities and the electrical tree growth conclude that it is handy for diagnosis the unseen electrical trees on related high-voltage insulation material by just using PD detection method

\section{ACKNOWLEDGEMENTS}

The authors gratefully acknowledge the financial support by Universiti Teknologi Malaysia and Universitas Sriwijaya under the research grants, Vot. Nos. 4B278, 4B279, 13H98, 4B340 \& 4B342 to carry out this work.

\section{REFERENCES}

[1] B. Du and Y. Gao, "Grow characteristics of electrical tree in silicone rubber," in Proceedings of the 16th International Symposium on High Voltage Engineering, Cape town, South Africa, 2009.

[2] M. H. Ahmad, N. Bashir, Z. Buntat, Y. Z. Arief, A. A. A. Jamil, M. A. M. Piah, A. A. Suleiman, S. Dodd and N. Chalashkanov, "Temperature Effect on Electrical Treeing and Partial Discharge Characteristics of Silicone RubberBased Nanocomposites," Journal of Nanomaterials, vol. 2015, p. 1-13, 2015.

[3] X. Yuan and Z. Tian, "Effect of ultrasonic on the properties of silicone/montmorillonite nanocomposites by in-situ intercalative polymerization., " Advanced Materials Letters, pp. 135-142, 2010.

[4] Q. Mu and S. Feng, "Thermal conductivity of Graphite/ Silicone Rubber prepared by solution intercalation," Thermochimica Acta, vol. 462, pp. 70-75, 2007.

[5] M. G. Danikas and T. Tanaka, "Nanocomposites-a Review of Electrical Treeing and Breakdown," IEEE Electr. Insul. Mag., vol. 25, pp. 19-25, 2009.

[6] T. Tanaka, "Dielectrics Nanocomposites with Insulating Properties," IEEE Trans. Dielectr. Electr. Insul., vol. 12, no. 5, pp. 914-928, 2005.

[7] S. Alapati and M. J. Thomas, "Electrical Treeing and the Associated PD Characteristics in LDPE Nanocomposites," IEEE Trans. Dielectr. Electr. Insul., vol. 19, no. 2, pp. 697-704, 2012.

[8] S. Singha and M. J. Thomas, "Dielectric Properties of Epoxy Nanocomposites," IEEE Trans. Dielectr. Electr. Insul., vol. 15, no. 1, pp. 12-23, 2008.

[9] T. Iizuka and T. Tanaka, "Effects of Nano Silica Filler Size on Treeging Breakdown of Epoxy Nanocomposites," IEEJ Trans. FM, vol. 130, no. 9, pp. 836-842, 2010.

[10] T. Tanaka, "Buds for Treeing in Epoxy Nanocomposites and their Possible Interaction with Nano Fillers," IEEE Int'l. Conf. Solid Dielectr. (ICSD), pp. 1-4, 2010.

[11] R. Kurnianto, Y. Murakami, N. Hozumi, M. Nagao and Y. Murata, "Some Fundamentals on Treeing Breakdown in Inorganic- filler/LDPE Nano-composite Material,” IEEE Trans. Dielectr. Electr. Insul., vol. 3, no. 17, pp. 685-693, 2001.

[12] J. K. Nelson and Y. Hu, "The Impact of Nanocomposite Formulations on Electrical Voltage Endurance," IEEE Int'l. Conf. Solid Dielectr. (ICSD), pp. 832-835, 2010. 
[13] Y. Murata, Y. Murakami, M. Nemoto, Y. Sekiguchi, Y. Inoue, M. Kanaoka, N. Hozumi and M. Nagao, "Effects of Nano-sized Mgo- filler on Electrical Phenomena under DC Voltage Application in LDPE," IEEE Conf. Elctri. Insul. Dielectr. Phenomena (CEIDP), pp. 158-161, 2005.

[14] Y. Chen, T. Imai, Y. Ohki and T. Tanaka, "Tree Initiation Phenomena in Nanostructured Epoxy Composites," IEEE Trans. Dielectr. Electr. Insul., vol. 17, no. 5, pp. 1509-1515, 2010.

[15] A. Jamil, , M. H. Ahmad, M. Kamarol and M. Mariatti, "Organo-Montmorillonite as an Electrical Treeing Retardant for Polymeric Insulating Materials," in Proceedings of the IEEE International Conference on Condition Monitoring and Diagnosis, Bali, Indonesia, 2012.

[16] I. L. Hosier, M. Praeger, A. S. Vaughan and S. G. Swingler, "Electrical Properties Of Polymer Nano-composites Based On Oxide And Nitride Fillers," in Electrical Insulation Conference (EIC), Seattle, Washington, USA, 2015.

[17] K. Y. Lau, A. S. Vaughan, G. Chen and I. L. Hosier, "On the dielectric response of silica based polyethylene nanocomposites," J. Phys. D: Appl. Phys, vol. 46, no. 095303, 2013.

[18] F. N. Musa, N. Bashir, M. H. Ahmad, Z. Buntat and M. A. M. Piah, "Investigating the influence of plasma-treated $\mathrm{SiO} 2$ nanofillers on the electrical treeing performance of silicone-rubber," Applied Sciences (Switzerland), vol. 6, no. 11, pp. 1-12, 2016.

[19] H. Zou, S. Wu and J. Shen, "Polymer/Silica Nanocomposites: Preparation, Characterization, Properties, and Applications," Chem. Rev., vol. 108, p. 3893-3957, 2008.

[20] E. P. Waldi, A. Aulia, A. Hazmi, H. Abral, S. Arief and M. H. Ahmad, "An optimized method of partial discharge data retrieval technique for phase resolved pattern," TELKOMNIKA (Telecommunication Computing Electronics and Control), vol. 14, no. 1, p. 21, March 2016.

[21] A. A. Jamil, M. H. Ahmad, M. Kamarol, M. Mariatti and M. M. Piah, "Short-term Breakdown in Silicone Rubber Based Nanocomposites Caused by Electrical Treeing," Advanced Materials Research, vol. 845, pp. 482-486, 2013.

[22] M. Musa, Y. Arief, Z. Abdul-Malek, M. H. Ahmad and A. Jamil, "Influence of nano-titanium dioxide (TiO 2) on electrical tree characteristics in silicone rubber based nanocomposite.," in Proceedings of the IEEE Conference on Electrical Insulation and Dielectric Phenomena, Shenzhen, China, 2013.

[23] M. Ahmad et al., "A New Statistical Approach for Analysis of Tree Inception Voltage of Silicone Rubber and Epoxy Resin under AC Ramp Voltage,” Int. J. Electr. Eng. Informatics, vol. 4, no. 1, pp. 27-39, 2012.

[24] F. Nabilah Musa, N. Bashir, M. Hafizi Ahmad, and Z. Buntat, "Electrical treeing in high voltage insulations: A review on nanocomposite insulating materials and their processing techniques," Journal of Optoelectronics and Advanced Materials, vol. 17, no. 3-4. pp. 462-476, 2015.

[25] G. Xu, J. Wang, X. Ji, J. Xiong and F. Li, "Effect of Nano-silicon Nitride on the Mechanical and Electric Properties of Polypropylene Nanocomposite,” Journal of Composite Materials, vol. 41, no. 18, pp. 2213-2223, 2007.

[26] I. L. Hosier, N. A. Freebody, A. S. Vaughan, S. G. Swingler and G. Moss, "Electrical Treeing in Silicone Rubber," in XVII International Symposium on High Voltage Engineering, Hannover, Germany, 2011.

\section{BIOGRAPHIES OF AUTHORS}

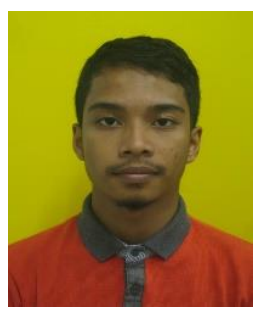

Abdul Hakim Mohd Nasib was born in Selangor, Malaysia in 1994. He received B.Eng. in electrical engineering from Universiti Teknologi Malaysia in 2016. He is currently pursuing his Master in Electrical Engineering at the Universiti Teknologi Malaysia. His resaech interests include nanodielectric and high voltage insulating materials.

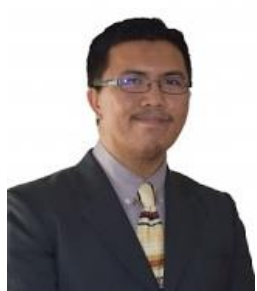

Mohd Hafizi Ahmad received his B. Eng and $\mathrm{PhD}$ degrees in Electrical Engineering from UTM, Malaysia in 2009 and 2013 respectively. He was formerly a visiting researcher in University of Leicester, UK and Tanjungpura University, Indonesia within 2010 and 2012. He worked as a tutor in the School of Electrical Engineering, UTM from 2009 to 2013. Currently, he works as a senior lecturer in the Institute of High Voltage and High Current (IVAT), School of Electrical Engineering, UTM. He is also a consultant and advisor for Global Testing Services (M) Sdn Bhd. His research interests cover different types of high voltage insulation, partial discharge measurement, nanodielectrics, condition monitoring and diagnostic, insulation performance and breakdown of dielectric materials. He is a member of IEEE and IET.

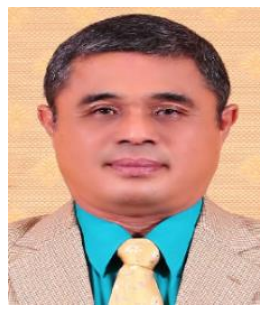

Zainuddin Nawawi was born in Lubuk Linggau, South Sumatera, Indonesia in 1959. He received Bachelor degree in electrical engineering from Sriwijaya University, Indonesia, and the Ph.D. degree from Universiti Teknologi Malaysia, Johor Bahru, Malaysia. He joined Department of Electrical Engineering of Sriwijaya University on 1984 and became a Professor in 2014. He was visiting researcher at IVAT-UTM, Malaysia from 2017 to 2018. Currently, he involves in several research projects on discharge in solid dielectric materials, application of plasma technology for medical equipment's sterilization, and lightning protection. He is a member of IEEE. 


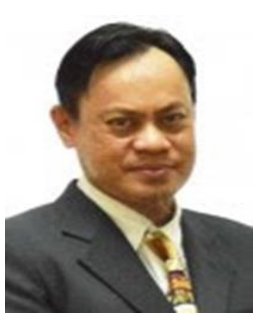

Muhammad Abu Bakar Sidik obtained bachelor of engineering (electrical) from Universitas Sriwijaya. Hereafter he obtained Master and Ph.D. degree from Universiti Teknologi Malaysia. Currently, he is an associate professor at Department of Electrical Engineering, Faculty of Engineering, Universitas Sriwijaya, Indonesia. His research interests are discharge phenomena in high voltage system.

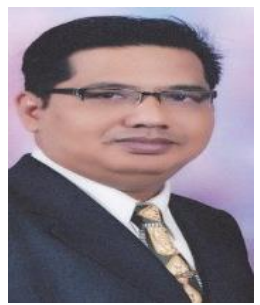

Muhammad Irfan Jambak received Bachelor in Electrical Engineering from Universitas Sriwijaya in 1996, M.Eng and PhD degrees from Universiti Teknologi Malaysia in 2002 and 2010 respectively. He is currently an associate professor at Department of Electrical Engineering, Faculty of Engineering, and Universitas Sriwijaya, Indonesia. His research interests cover high voltage engineering and lightning protection. 